\title{
Transoral laser microsurgery for laryngeal cancer: A primer and review of laser dosimetry
}

\author{
Marc Rubinstein • William B. Armstrong
}

Received: 2 December 2009 / Accepted: 13 August 2010 /Published online: 11 September 2010

(C) The Author(s) 2010. This article is published with open access at Springerlink.com

\begin{abstract}
Transoral laser microsurgery (TLM) is an emerging technique for the management of laryngeal and other head and neck malignancies. It is increasingly being used in place of traditional open surgery because of lower morbidity and improved organ preservation. Since the surgery is performed from the inside working outward as opposed to working from the outside in, there is less damage to the supporting structures that lie external to the tumor. Coupling the laser to a micromanipulator and a microscope allows precise tissue cutting and hemostasis; thereby improving visualization and precise ablation. The basic approach and principles of performing TLM, the devices currently in use, and the associated dosimetry parameters will be discussed. The benefits of using TLM over conventional surgery, common complications and the different settings used depending on the location of the tumor will also be discussed. Although the $\mathrm{CO}_{2}$ laser is the most versatile and the best-suited laser for TLM applications, a variety of lasers and different parameters are used in the treatment of laryngeal cancer. Improved instrumentation has lead to an increased utilization of TLM by head and neck cancer surgeons and has resulted in improved outcomes. Laser energy levels and spot size are
\end{abstract}

This work was presented at the 29th Annual Conference of the American Society for Laser Medicine and Surgery. April 1-5, 2009, National Harbor, Maryland.

M. Rubinstein · W. B. Armstrong $(\bowtie)$

Department of Otolaryngology - Head and Neck Surgery,

University of California Irvine,

101 The City Drive S, Bldg 56 Room 500,

Orange, CA 92868, USA

e-mail: wbarmstr@uci.edu

M. Rubinstein

Beckman Laser Institute and Medical Clinic,

University of California Irvine,

Irvine, CA, USA adjusted to vary the precision of cutting and amount of hemostasis obtained.

Keywords Laser - Microsurgery - Laryngeal cancer $\cdot \mathrm{CO}_{2}$. Endoscope

\section{Introduction}

Over the last 50 years, advances in the management of laryngeal cancer have resulted in treatments with increased effectiveness as well as improved function. With the development of new conservation surgical techniques, advances in delivery of radiation treatments, and development of organ preservation regimens using chemotherapy (CT) combined with radiotherapy (RT), decision-making has become more complex.

Over the last 20 years, organ preservation surgery has evolved from standard external surgical approaches to resect cancer and preserve parts of the larynx to surgical procedures resecting equivalent tumors performed through an endoscope. These operations turn the operative paradigm "inside out". They require re-learning the surgical anatomy from a new perspective, and development of skills to resect tumors through the lumen of long, narrow endoscopes. This has required critical examination and validation of oncological effectiveness of surgical resection, and surgeons learning a new skill set to successfully perform these procedures.

This review outlines the development of transoral laser microsurgery (TLM), provides rationale for treatment selection, describes a practical description of surgical technique, and analyzes technical factors associated with the use of the carbon dioxide laser in surgical management of laryngeal cancer. 


\section{Epidemiology}

Laryngeal cancer is the second most common cancer in the upper aerodigestive tract, with over 12,000 new cases a year in the United States and nearly 3,000 annual deaths [1]. Approximately $95 \%$ of laryngeal cancers are squamous cell carcinomas (SCC), and a significant majority occur in patients between 60 and 70 years old [2]. The overall 5-year survival rate for laryngeal SCC is $64 \%$ [3]. The risk of developing laryngeal SCC has been closely related to tobacco and alcohol use, and is proportional to the amount and duration of use. Furthermore, tobacco and alcohol act synergistically [4-8]. Other potential risk factors for laryngeal SCC include laryngopharyngeal reflux $[9,10]$, as well as occupational exposure to asbestos and other environmental toxins. Because of confounding variables and low prevalence of most occupational exposures, definitive assessment is difficult and the contribution of these factors is debated $[11,12]$. In recent years, a relationship between human papillomavirus (HPV) and head and neck cancer has been elucidated. Although the association is strongest for pharyngeal cancers, there appears to be at least a weak association with development of laryngeal cancer [13-15]. Genetic predisposition is also a contributing factor for the likelihood of developing HNSCC, partially explaining why some heavy smokers and drinkers fail to develop cancer, while some young persons with no significant exposure to tobacco, alcohol, or HPV exposure develop aggressive tumors [16].

\section{Anatomy and staging}

The larynx is a complex organ with a primary evolutionary function to protect the lungs from aspiration of food and water, with phonation and voice production as secondary adaptations. The larynx is composed of cartilages, connective tissue barriers, muscles, and soft tissues that act in a coordinated fashion to allow sphincteric control of the airway. The larynx is divided anatomically into the supraglottic, glottic, and subglottic regions, and is illustrated in Fig. 1. A full description of laryngeal anatomy is beyond the scope of this article, and the reader is directed to the references sited below [17-19].

Head and neck cancer is also a heterogeneous disease, with different behavior and prognosis at each region of the head and neck, and within the larynx between the three subsites. Prognosis and treatment selection is dependent in large part on tumor staging using the TNM staging system of the American Joint Committee on Cancer (AJCC). Staging is based on the anatomical location of the tumor, tumor spread to the cervical lymph nodes, and distant metastasis. Using the TNM stage, patients are divided into four stage groups (I-IV), which provides a good stratification of survival probability and aids selection of appropriate treatment modalities. A full description of the staging system is provided in the AJCC staging manual [20].

Early stage cancer (stages I and II) is generally managed with single modality therapy, and treatment selection is based primarily on treatment morbidity as surgery and RT generally have similar cure rates. For advanced stage (stages III and IV) disease, combined modality therapies are generally used, and decisions regarding the ability to preserve the larynx are critical.

Endoscopic approaches to manage laryngeal cancer have developed over the last 30 years, and with increased anatomic understanding, clinical experience, and longterm results demonstrating oncological efficacy, transoral laser microsurgery (TLM) on the larynx has become an accepted treatment modality for both early laryngeal cancer, and as an organ preservation technique for advanced laryngeal cancers.

\section{Overview of treatment options for laryngeal cancer}

\section{Surgical treatment}

Total laryngectomy is performed for advanced laryngeal cancer, and is the gold standard oncologically. It is also debilitating, relegating recipients of this procedure to breathing through an artificial stoma in the neck, and learning alternative methods to speak without a voice box. Dissatisfaction with the morbidity of the total laryngectomy led to progressive development of conservation surgical procedures to remove portions of the larynx. For glottic tumors, removal of the vocal cord (cordectomy) and external vertical partial laryngectomy were developed to treat early glottic cancers. For supraglottic cancer, the supraglottic laryngectomy, which removes the epiglottis, preepiglottic space, and false vocal cords, was developed to preserve speech function and avoid a permanent stoma or tracheostomy $[21,22]$. When contemplating conservation surgery, it is important to consider several basic concepts when evaluating if a patient is eligible for a conservation laryngectomy. It is critical to be able to accurately assess the complete tumor extent, and determine if the tumor can be resected with adequate oncologic margins and preserve the critical structures necessary for maintenance of laryngeal function to preserve the airway and maintain adequate phonatory function. The cricoarytenoid unit forms the basic functional unit of the larynx. Fundamentally, adequate laryngeal function requires preservation of at least, one functional cricoarytenoid joint, and the cricoid cartilage for the patient to be a candidate for conservation laryngectomy. [23]. 
Fig. 1 Diagram of the larynx showing the different sites and subsites (adapted from Coates GM, Schenck HP. Otolaryngology. W.F. Prior Co., Hagerstown, MD. 1966, Vol. 5, Chapter 7, page 4)

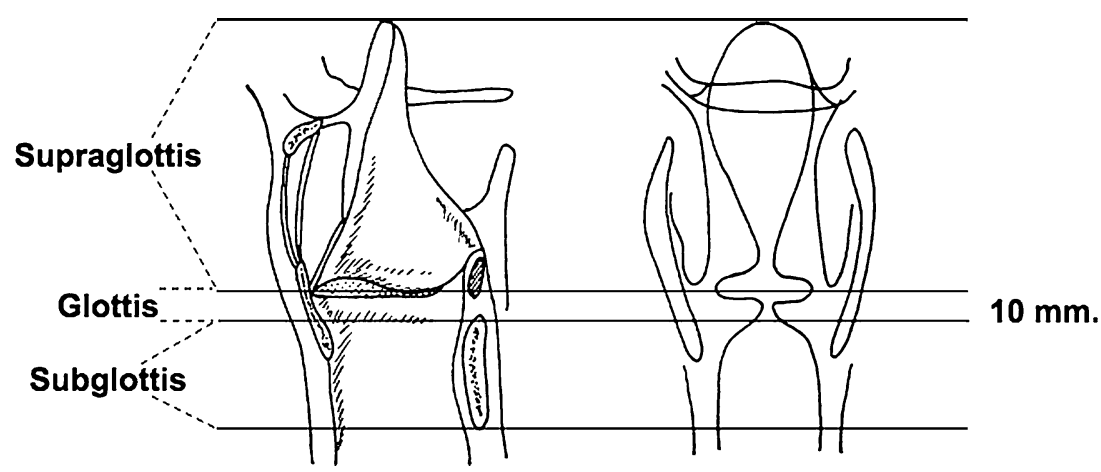

Open conservation laryngeal resection (partial laryngectomy) is oncologically effective when performed on appropriately selected patients by competent surgeons. A limitation of open procedures is that intervening normal structures are either transected or resected to access the intraluminal tumor from an external approach. Open surgical approaches disrupt the strap muscles, laryngeal cartilages, nerves, and blood supply to tissues external to the tumor. This results in postoperative swelling necessitating temporary tracheostomy, impairment of laryngeal elevation, and loss of sensation, resulting in swallowing dysfunction and aspiration in the postoperative period. Chronic aspiration is the norm with open supraglottic laryngectomies. This limited the number of patients who were eligible for these procedures to those with good pulmonary function who could withstand several months of chronic aspiration while they heal and re-learn how to swallow. Open resection of glottic tumors results in postoperative airway swelling necessitating tracheostomy, either from the resection, or the soft tissue reconstructions designed to restore soft tissue removed during resection of the tumor. Because of the soft tissue disruption, airway stenosis from scarring and/or extensive atrophy resulting in aphonia are common and often lead to unpredictable functional outcomes. These limitations of traditional open conservation approaches led to efforts to develop endoscopic techniques to treat laryngeal cancers, described below.

\section{Radiation therapy}

Radiation therapy is an effective treatment for early laryngeal cancers. Treatment is performed daily over a 5-7 week period. It has the advantage of being a nonsurgical modality, and voice outcome for glottic cancer is generally very good. There are several limitations to primary RT. The primary limitation is RT generally cannot be repeated for curative purposes if there is recurrence, or a second primary in the previously radiated field [24]. RT is often used with other treatment modalities. Postoperative RT is used in locally advanced laryngeal tumors to decrease recurrence [25]. It is also used with $\mathrm{CT}$ in a variety of organ preservation regimens described below [26].

Photodynamic therapy (PDT) is a treatment modality that has demonstrated effectiveness, especially for superficial head and neck cancers. A light-activated pro-drug is administered, and it accumulates preferentially in cancer cells. The drug is activated by light of a specific wavelength catalyzing reactions that result in release of oxygen free radicals that are cytotoxic to the cells accumulating the drug. PDT produces a variable length of photosensitivity following treatment that is dependent on the agent used. Although impressive results have been reported [27, 28], the technique is not yet widely available.

\section{Organ preservation strategies}

In 1991, the Department of Veterans Affairs Laryngeal Cancer Study Group published a landmark randomized controlled clinical trial comparing an organ preservation protocol with total laryngectomy. Induction CT followed by RT in clinical responders in carefully selected laryngeal cancer patients produced an equivalent cure rate to those patients receiving TL, while preserving the larynx in approximately two-thirds of cases [29]. This trial demonstrated the oncologic viability of organ preservation of the larynx, and launched a new trend for organ preservation in selected advanced laryngeal cancers. In 2003, the Radiation Therapy Oncology Group and the Head and Neck Intergroup published a trial (RTOG 91-11) that confirmed that the use of concurrent chemoradiation therapy (CRT) significantly improved locoregional control and organ preservation compared to $\mathrm{CT}$ followed by adjuvant RT or RT alone [30], making concurrent CRT a new organ preservation treatment standard for selected advanced laryngeal cancers. Subjects receiving radiation alone did not fare as well as either the concomitant or neoadjuvant CT groups. This study excluded advanced T4 lesions with cartilage invasion or extralaryngeal spread [26]. Since the introduction of organ preservation strategies, the indication for radical surgery, a total laryngectomy (TL), has declined. 
The combination of $\mathrm{CT}$ and $\mathrm{RT}$ is a very aggressive treatment regimen. Mortality of up to $4 \%$ has been reported in major series [31]. Many patients undergoing these treatments experience prolonged loss of swallowing function, and in a minority of patients, long-term fibrosis results in anatomic preservation of a nonfunctional larynx. TL is indicated when the disease cannot be treated with partial laryngectomy, CT or RT, or when the laryngeal tumor has invaded extralaryngeal tissues of the neck [32].

\section{Transoral laser microsurgery (TLM) for laryngeal cancer}

\section{What is TLM?}

Transoral laser microresection, in laryngeal cancer is the oncologic resection of tumors performed through an endoscopic as opposed to an external surgical approach. Tumors are visualized through an endoscope, resected using lasers or other cutting and coagulation methods, and the wound bed is left open to heal by secondary intention.

\section{Historical development}

The historical evolution of TLM for laryngeal cancer goes all the way back to the early days of laryngeal surgery. Chevalier Jackson was perhaps the first to endoscopically resect a tumor of the epiglottis through an endoscope with cup forceps in 1915 [33, 34]. Because of very primitive equipment, the ability to perform transoral resections of tumors was limited, and tumor resections of the larynx were only occasionally performed.

As laryngology developed, technological advances laid the groundwork to allow endoscopic surgical resections. The first advance was the development of fiber-optic light sources, to allow distal illumination of the airways. A second important advance was the development and use of the operative microscope, which allowed magnified views of the larynx. In conjunction with magnification was the development of smaller instruments adapted from otologic instruments to manipulate tissues within the larynx. The critical advance that allowed transoral laser microsurgery to develop was coupling of the newly developed carbon dioxide laser to the microscope and developing micromanipulators to precisely deliver energy to the larynx. In 1972, Strong and Jako [35] coupled a $\mathrm{CO}_{2}$ laser to a surgical microscope for use through a laryngoscope, introducing a new modality for the treatment of benign laryngeal pathologies. Three years later, in 1975, Strong [36] used the $\mathrm{CO}_{2}$ laser to successfully treat 11 patients with early T1 laryngeal cancer. In 1978, Vaughan [37] first reported the use of the $\mathrm{CO}_{2}$ laser to resect supraglottic tumors. Based on the early work by Strong and Vaughan, Steiner [38-41] worked to develop new endoscopes to aid exposure, developed sturdy instruments to grasp and retract the larynx, worked out techniques to obtain and maintain hemostasis through the endoscope, and importantly demonstrated that tumors could be resected in sections with oncologic safety. Importantly, these techniques have been adapted by others [42-48], and the oncologic effectiveness has been replicated, treating different stages and locations of laryngeal cancer.

The indications for TLM parallel those for open conservation surgery. The tumor must be oncologically amenable to surgical resection for cure. In addition to the oncological indications is the ability to visualize the tumor through the endoscope. Anatomic factors that limit the ability to expose the larynx include trismus, inability to extend the neck, a large tongue base, prominent dentition, and other anatomic factors that prevent the insertion of endoscopes to expose the tumor (see Table 1). TLM has several advantages over traditional open surgery, namely a lower incidence of complications in comparison to open surgery, such as a decrease in the need for tracheostomy [46, 49], pharyngocutaneous fistulas [49], and lower postoperative morbidity [24].

The $\mathrm{CO}_{2}$ laser has an infrared beam with a wavelength of $10.6 \mu \mathrm{m}$. It is delivered into the airway along the axis of the microscope visual field using a micromanipulator coupled to the microscope. The micromanipulator allows precise control of beam delivery to precisely cut through tissues and obtain hemostasis. The carbon dioxide laser has ideal tissue properties for surgery in the larynx because of its high coefficient of extinction in water, which limits soft tissue penetration and minimizes collateral thermal effects, while providing generally adequate hemostasis. Recently, laser delivery through a flexible hollow tube has become available to deliver the laser beam close to the target. The advantage of the flexible systems is the ability to have limited bending of the fiber within the endoscope to vary the angle of attack for cutting through tissues and to allow easier access to some

Table 1 Indications and contraindications for TLM in malignant lesions

\begin{tabular}{l}
\hline INDICATIONS \\
- Tumors amenable to conservation laryngeal surgery T1, T2, and \\
selected T3 tumors \\
- Ability to adequately expose the larynx \\
- Palliative tumor debulking \\
CONTRAINDICATIONS \\
- Extensive tumors \\
O Extralaryngeal tumor spread \\
- Inability to preserve cricoid and one arytenoid \\
- Inadequate endoscopic access
\end{tabular}


areas that are difficult to reach with traditional laser systems. The primary limitations of these systems are limited angulation and as with use of standard microlaryngeal instruments, the effect of natural surgeon tremor is magnified along the shaft of the instrument $[50,51]$.

Although the $\mathrm{CO}_{2}$ laser was the first to be used in the larynx, a number of other lasers have been used within the larynx. They differ in method of delivery of the energy, tissue penetration, and tissue cutting and hemostatic capabilities. The KTP $(532 \mathrm{~nm})$ laser has excellent hemostatic properties with a slight increase in the depth of tissue injury. It is delivered through a quartz fiber, which for selected tumors can be advantageous. Recently, pulsed KTP lasers have become available for tissue photoablation. For premalignant lesions, and selected early glottic carcinomas, experience with 585- and 595-nm pulsed dye lasers has been reported $[48,52]$. Other lasers, including thulium and gold lasers, have recently become available and are being evaluated [53-55].

\section{Operative technique}

Thorough and accurate preoperative evaluation and staging are critical for operative success. The lesion must be accurately visualized either in the office or through operative endoscopy, and histological confirmation of malignancy is mandatory. For larger tumors, imaging with MRI or CT scan is performed to evaluate for both hidden deep invasion of tumor, and nodal metastases. Once the patient is in the operating room under general anesthesia, a confirmatory direct laryngoscopy is performed. Before starting the laser resection, it is very important to implement several laser safety measures to minimize the risk of complications from the laser surgery. The primary risks of the laser are burns to the patient and members of the operative team. First it is important to protect the

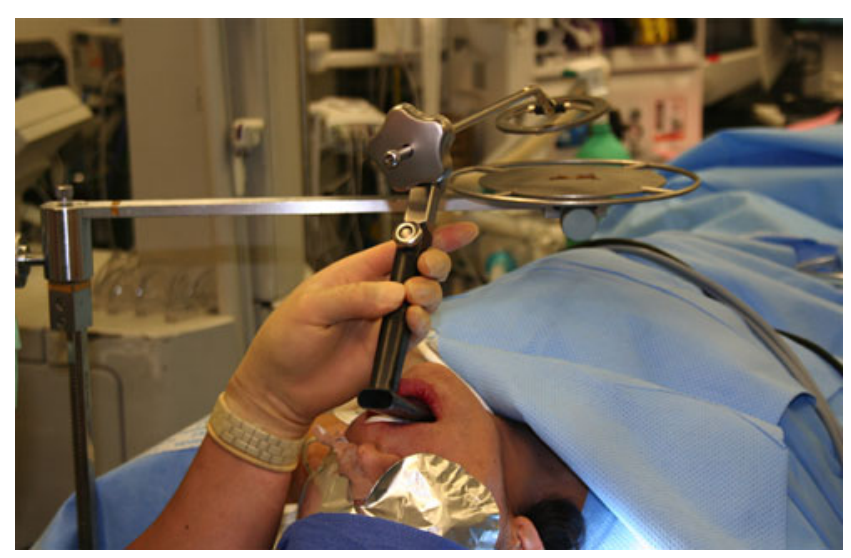

Fig. 2 Image showing the eye protection used in patients undergoing laser procedures patient's eyes with protective eye pads wet with saline (Fig. 2). Likewise, all operative personnel must wear protective eyeglasses. Signs are placed outside the OR to indicate that a laser is in use. The facial skin is protected using surgical towels soaked in saline solution, and these towels need to be kept wet during the entire procedure. A smoke evacuator is used to remove laser plume created by the laser. We use a protected endotracheal tube designed to decrease the risk of ignition from laser impact (Fig. 3). The cuff of the laser-protected tube is inflated using saline with methylene blue dye to help identify endotracheal tube cuff rupture, and help prevent tube ignition if there is cuff damage during the procedure. Irrigation solution with bulb syringes is immediately available in the event of ignition of the drapes or other flammable materials. The oxygen concentration is also lowered to below $30 \% \mathrm{FiO}_{2}$ when using the laser to decrease the likelihood of fire [56]. In the event of an airway fire, the endotracheal tube is immediately removed, the airway is re-secured, bronchoscopy is performed, and the procedure is terminated.

Once the patient is prepared, the patient is placed in a supine position with the head fully extended. The dentition is protected using either a plastic or metal tooth guard, or as we prefer, a custom thermoplastic splint to cover the teeth. Using one of a variety of rigid laryngoscopes selected to visualize the desired structures (Fig. 4), the larynx is visualized through the laryngoscope (Fig. 5). Once adequate exposure is obtained, the laryngoscope is fixed using a suspension arm (Fig. 6). Laryngeal suspension frees both hands for operative manipulation.

The microscope is brought into position and the laser is coupled to the micromanipulator (Fig. 7). Along with the invisible $\mathrm{CO}_{2}$ laser beam is a coaxial helium-neon (He-Ne) laser aiming beam to align the laser to the target. Prior to surgery, the laser is tested to ensure both proper function and alignment of the $\mathrm{CO}_{2}$ and $\mathrm{He}-\mathrm{Ne}$ beams.

The primary advantage of the $\mathrm{CO}_{2}$ laser coupled to a micromanipulator is that precise tissue cutting and coagulation can be achieved, which reduces the collateral damage to the surrounding tissues. Because the laser is delivered from a joystick-controlled micromanipulator, there is unimpaired visualization of the target, limited motion artifact from surgeon tremor, and one hand remains free to retract tissues or suction out debris while operating the laser (Fig. 8).

Small tumors (e.g., small superficial T1 glottic tumor) can be resected en bloc by cutting around the tumor and removing it in one piece. Another option for small tumors, especially if the tumor is more infiltrating is to cut the tumor in half to definitively establish depth of invasion and then remove it in two pieces. For larger tumors, en bloc resection is either challenging or impossible. For larger tumors, the tumor is removed in sections starting at one end 
Fig. 3 Specialized laser-resistant protected endotracheal tube covered with an aluminum wrap

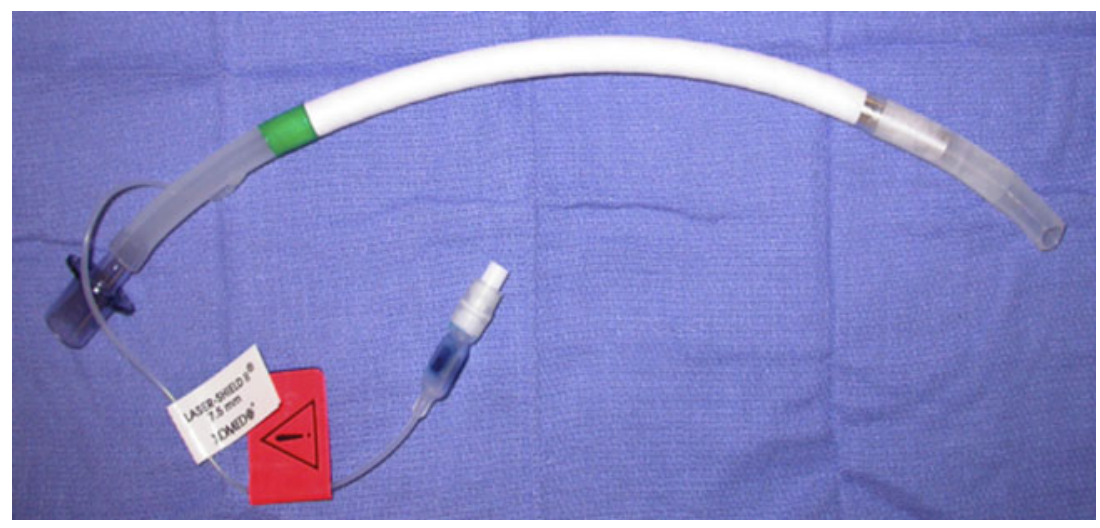

of the tumor, working systematically across the tumor to completely resect the tumor. This technique initially came under significant criticism because it violated classic Halstedian principles of en bloc resection. Extensive study by Steiner [39, 57] and others [45, 58-60] has demonstrated that there is no sacrifice of oncologic control using a blockwise resection of the tumor in discrete segments.

An advantage of removing the tumor in sections is the ability to precisely define the depth of tumor invasion. A significant risk of en bloc resections is the inability to determine the depth of tumor penetration, and there is a risk of unknowingly resecting too close to the tumor margin at the deepest and least accessible portion of the tumor. By cutting directly through the tumor under high magnification, the depth of tumor penetration can be seen and appropriate deep margins delineated.

Once the larynx is exposed and the tumor and surrounding structures are visualized, the surgeon marks the peripheral margins using the $\mathrm{CO}_{2}$ laser. The size of the margin depends

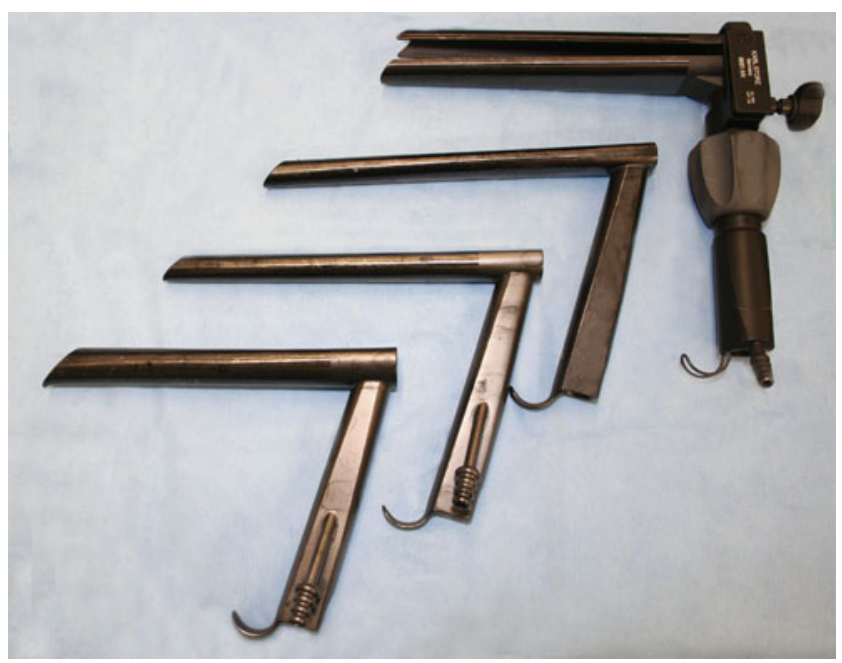

Fig. 4 Selection of various laryngoscopes used in TLM for tumor exposure on the location and stage of the tumor and if the patient is undergoing primary treatment or resection of recurrent disease. If there has been prior RT, wider margins are taken because of the higher risk of an infiltrative pattern of spread through the tissues. For small glottic tumors, a margin of as little as $1 \mathrm{~mm}$ is necessary. For deep margins, several millimeters, and ideally a connective tissue barrier are chosen for margins of resection.

Successful resection of tumors requires the laser to perform a variety of tasks from tissue ablation, precise cutting, and coagulation of tissues. These tasks require different techniques and differing laser energies, spot sizes, and pulse modes. It is important to emphasize that for a given application, there are no fixed settings, and that practice patterns vary significantly by physician. Several laser parameters are selected for each particular case, including: (a) power, (b) spot size, (c) exposure time, and (d) power (pulse) delivery. Laser energy can be delivered through intermittent pulses, repeated pulses, continuous wave $(\mathrm{CW})$, or use of very rapid (millisecond) pulse delivery in the form of ultrapulse or superpulse mode.

$\mathrm{CW}$ mode produces surrounding tissue damage from thermal spread of the laser energy. In order to produce adequate cutting and hemostasis with limited char formation and thermal spread, alternative pulse delivery modes have been developed to allow tissue cutting and hemostasis while limiting thermal damage to surrounding tissues. By producing high-energy, short-duration pulses in rapid succession, tissue ablation can occur with limited heat damage to surrounding tissues. The two most common modes, ultrapulse and superpulse, utilize slightly different strategies to produce rapidly pulsed waves that incorporate high peak power delivered in millisecond pulses. Superpulse mode delivers short bursts (less than $1 \mathrm{~ms}$ ) in rapid succession. The energy profile of the beam is characterized by a high initial peak energy spike with rapid drop in energy over duration of the pulse. The ultrapulse mode delivers a short pulse with a rapid peak onset, relatively constant energy delivery for the duration of the pulse, and 
Fig. 5 a Insertion of laryngeal endoscope through the oral cavity to visualize the laryngeal structures. b Classical view through the laryngoscope, where the vocal cords are seen
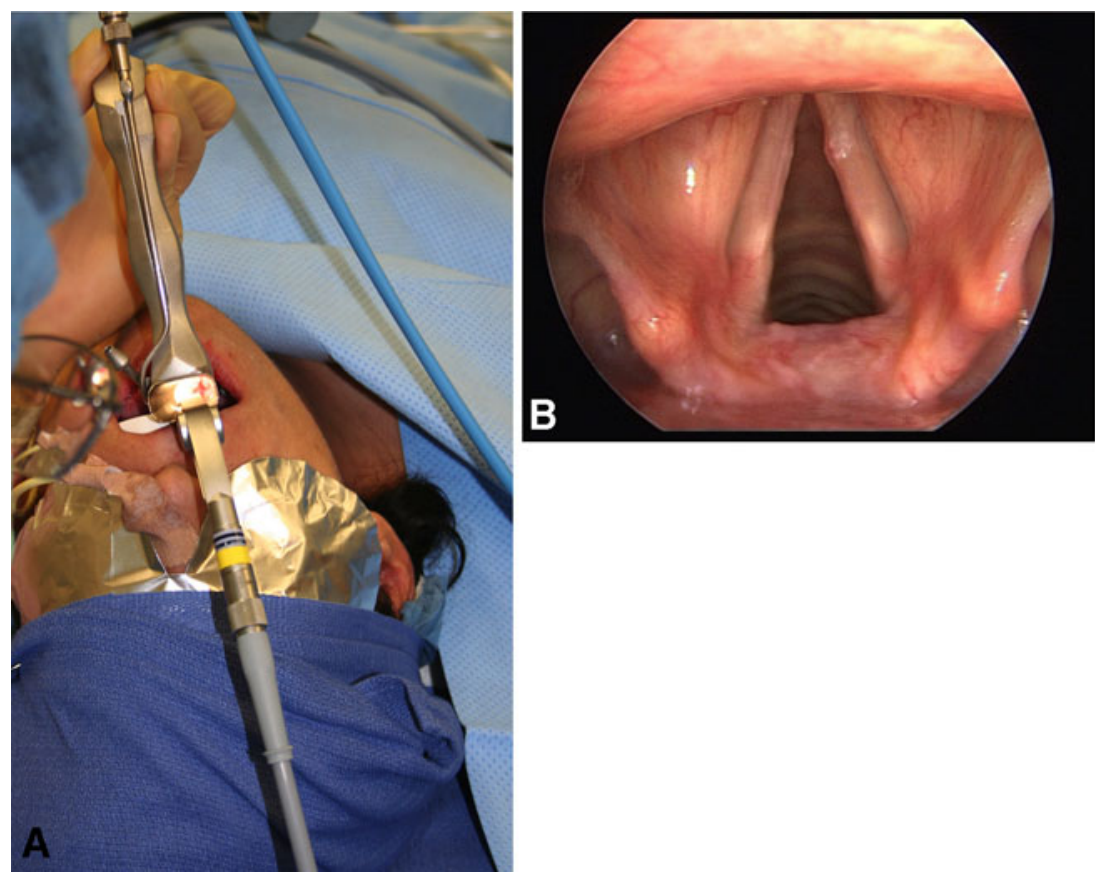

rapid decline in power at the end of the pulse, approximating a square wave. The superpulse mode has higher peak energy but less total energy delivery per pulse and more rapid pulse delivery, while ultrapulse mode has lower peak energy in each pulse, higher energy delivered with each pulse, and longer duration between pulses [61, 62]. From a practical standpoint, the clinical differences between the two pulse modes is subtle, although the thermal damage from the superpulse mode is reported to be slightly greater than with utrapulse mode than the superpulse mode [62].

There is no "cookbook" formula for selecting laser energy, spot size, or pulse duration, but basic principles for different operative tasks can be summarized as follows:

- When cutting through gross tumor it is necessary to increase the power as high as $20 \mathrm{~W}$ and with a beam

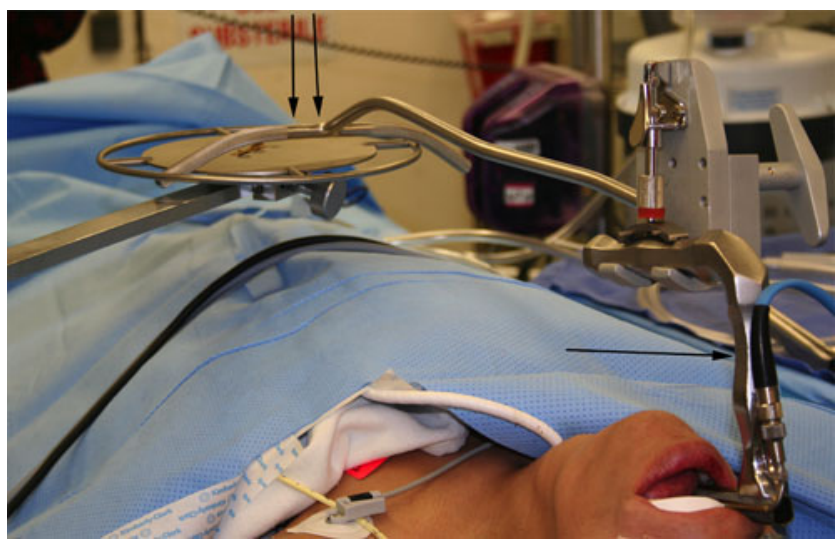

Fig. 6 Patient under suspension laryngoscopy, using a laryngoscope (arrow) and a suspension arm (double arrow) diameter as low as $400 \mu \mathrm{m}$, using a continuous wave pulse to rapidly penetrate the tumor and have adequate hemostasis.

- Utilize traction and counter traction to place tissues on tension. As the laser cuts through the tissues, they separate; exposing underlying structures and this also produces decreased char formation.

- When dissecting near large vessels or nerves, it is important to decrease power, defocus the beam to increase spot size, and utilize conventional dissection techniques to expose vessels and nerves.

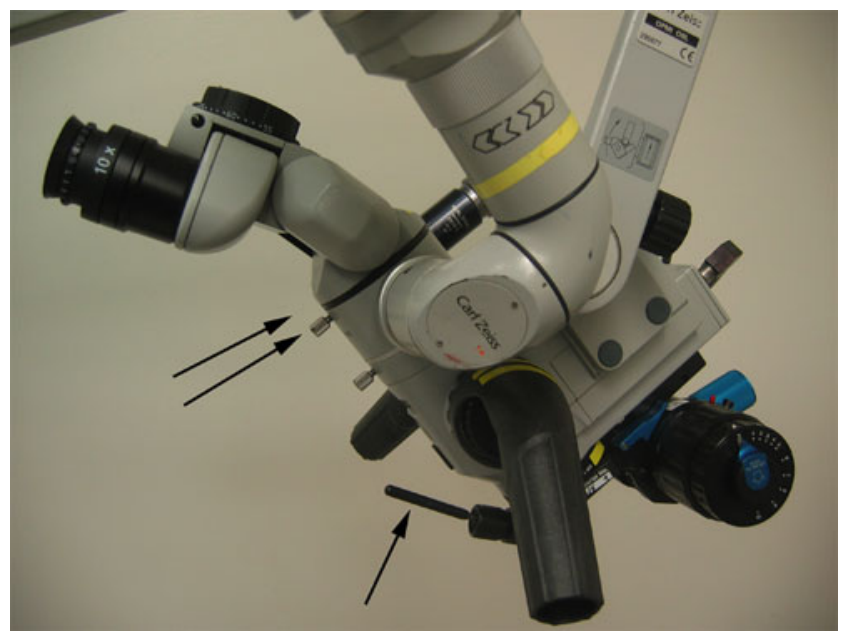

Fig. 7 Surgical microscope (double arrow) used in TLM, coupled with a micromanipulator (single arrow) 
Fig. 8 Specially designed microlaryngeal instrumentation for the use in TLM. a Forceps and scissors. b Insulated cannula for suction and unipolar coagulation
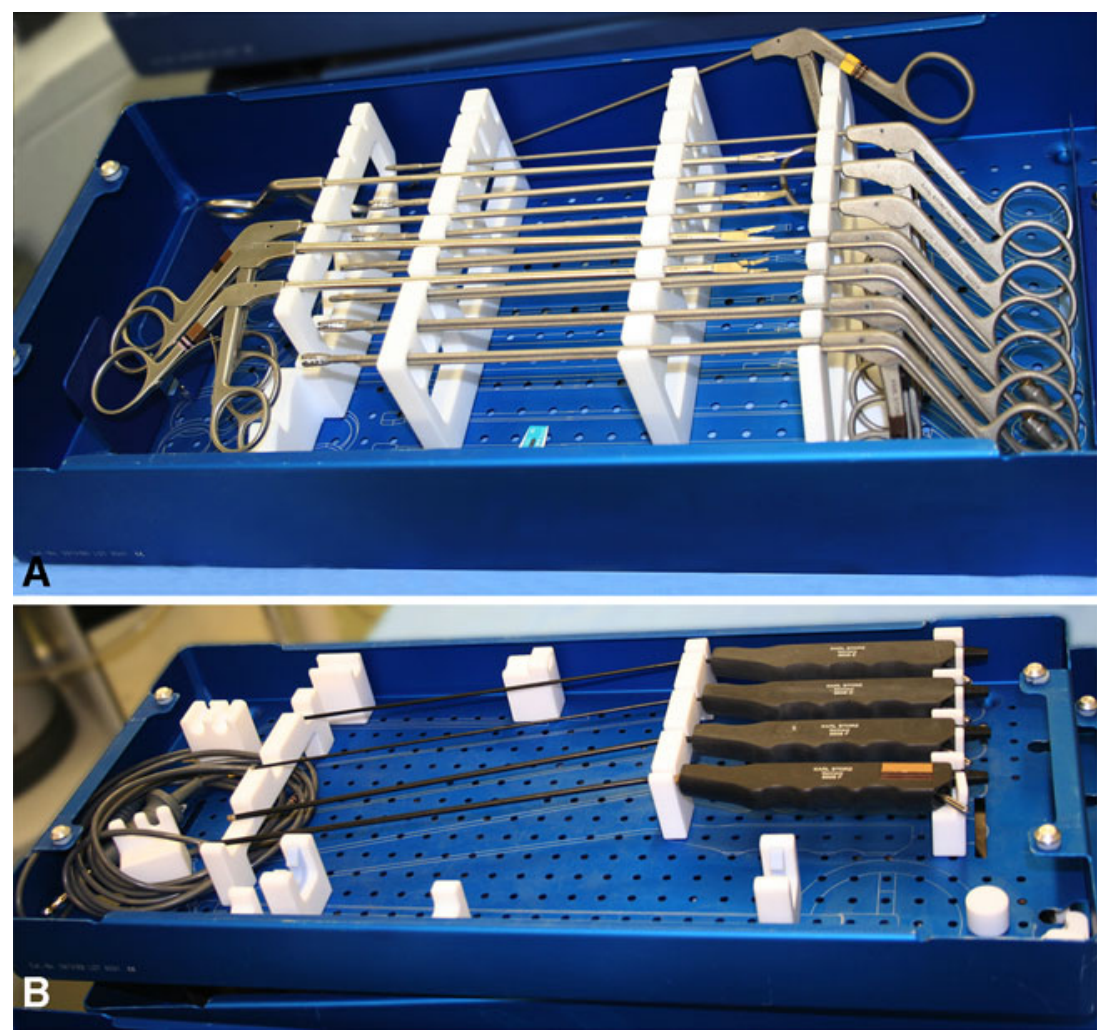

- For small- to intermediate-size vessels (up to approximately $1 \mathrm{~mm}$ ), improved hemostasis is achieved using a defocused beam with increased power.

- Large vessels will not be handled adequately with the laser. Liberal use of hemostatic clips, bipolar cautery, or monopolar cautery is recommended for medium- to larger-sized vessels.

- Ultrapulse and superpulse modes are generally used to define margins, cut through normal tissues, and to perform precise tissue dissection. They produce less surrounding damage and char formation, which results in better anatomic visualization. Decreasing the peak pulse energy results in decreased penetration with each pulse and is useful for fine dissections.

- Ultrapulse and superpulse modes are also helpful for cutting through bone or cartilage when used with high power settings.

As the tumor is removed in sections, the specimens are carefully labeled and oriented for the pathologist. Often, marking ink used by the pathologist is placed on the true margins in the operating room by the surgeon. It is critical to have precise communication and collaboration with the pathologist to correctly interpret margin status for these complex specimens. In complicated cases, the specimen is often delivered to the pathologist managing the case by the surgeon to ensure correct orientation of the specimen.
Frozen-section margins are sent based on the surgeon's judgment of areas at greatest risk for recurrence. If positive margins are reported by the pathologist, additional tissue is removed until the margins are clear (Fig. 9). Following resection, hemostasis is ensured, and the wound is left open without reconstruction to heal by secondary intention (Fig. 10).

\section{Postoperative care and feeding}

The postoperative care regimen of the patient is tailored to the extent of the resection. The two most critical concerns are postoperative bleeding into the airway, and airway obstruction from edema. Thus, for larger resections or those involving the supraglottis, the patient is initially managed in the ICU. After $48 \mathrm{~h}$, the risk of major bleeding is significantly decreased, although there can be delayed hemorrhage from sloughing of eschar after 7-10 days. If there is significant bleeding, securing the airway through intubation, or if necessary, tracheostomy is of primary concern to prevent drowning from aspirated blood.

Once the patient is awake and stable, oral alimentation with ice chips and water is started. This clears secretions and inflammatory materials, and helps keep the wound bed clean. Diet is advanced as tolerated. Decisions regarding oral alimentation rest on the extent of the resection, and patient factors. If the patient is expected to have compro- 
Fig. 9 Schematic depiction of how the tumor of the larynx is removed. It is removed by cutting through the tumor and removing it in sections
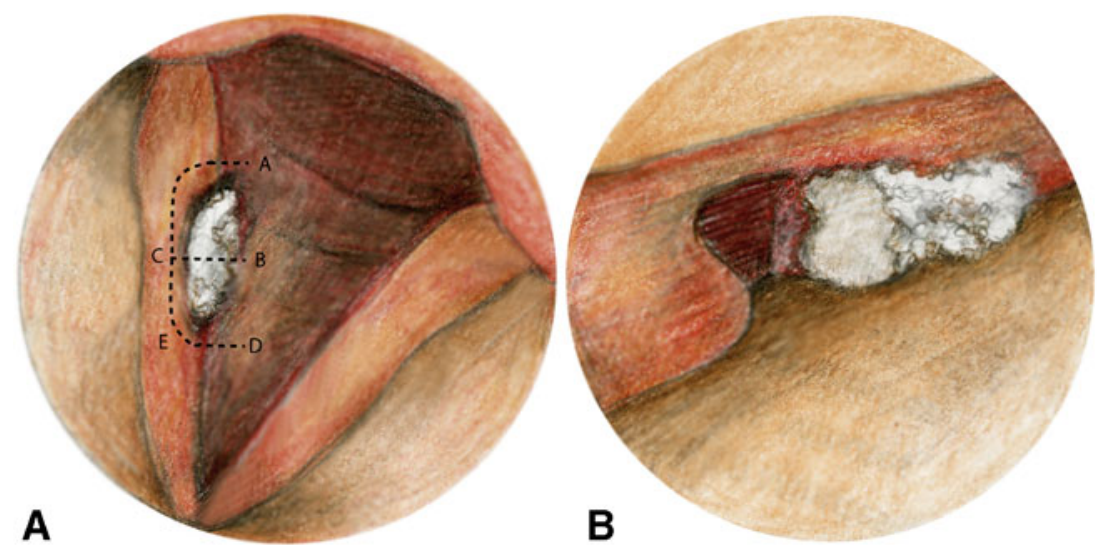

mised swallowing based on age, preoperative swallowing function, mental status, or prior radiotherapy, a nasogastric feeding tube is placed and swallowing evaluations are obtained. Antibiotics to cover oral flora are given for $24 \mathrm{~h}$, and surgical practices vary, with some practitioners stopping at $24 \mathrm{~h}$, and others providing more extended coverage after discharge because of the large open wound in a contaminated field.

The final pathologic findings and margin status are reviewed carefully to ensure complete tumor eradication. If there are positive or close margins, the location is determined based on review of the specimens with anatomic maps of the resection. A second procedure to remove focal areas where there are close or positive margins is performed. Depending on the oncological stage, the likelihood of need for a second resection ranges from as low as $5 \%$ in early glottic carcinoma to up to $29 \%$ in advance tumors, to definitively clear close or positive margins [57, 63-65].

\section{Complications}

In general, TLM is well tolerated with low complication rates, and generally improved functional outcome compared to corresponding open procedures resecting the same size tumor. Early postoperative hemorrhage (described above) is a potentially lethal complication. Often there will be a small amount of bleeding, but significant bleeding from a major artery in the larynx can result in aspiration of blood into the airway. It is critical in this situation to secure the airway, either by endotracheal intubation or by performing a tracheostomy, followed by operative control of hemorrhage. Airway obstruction is uncommon, as resection of the tumor generally provides an airway that is more widely patent following surgery. Since the neck is not incised, there is much less postoperative swelling and edema that characterizes open surgical procedures on the larynx. However, prolonged tongue retraction and compression during long operations can result in soft tissue ischemia, and in tongue edema postoperatively. Additionally, prolonged displacement of the tongue by the laryngoscope can cause temporary lingual or hypoglossal paresis. In cases lasting more than $1-2 \mathrm{~h}$, periodically releasing suspension to allow blood flow to the tongue markedly decreases the likelihood of developing postoperative tongue swelling or nerve dysfunction. The neuropathy caused by retraction is temporary, and generally resolves over several weeks. Also mentioned under postoperative care, aspiration can be
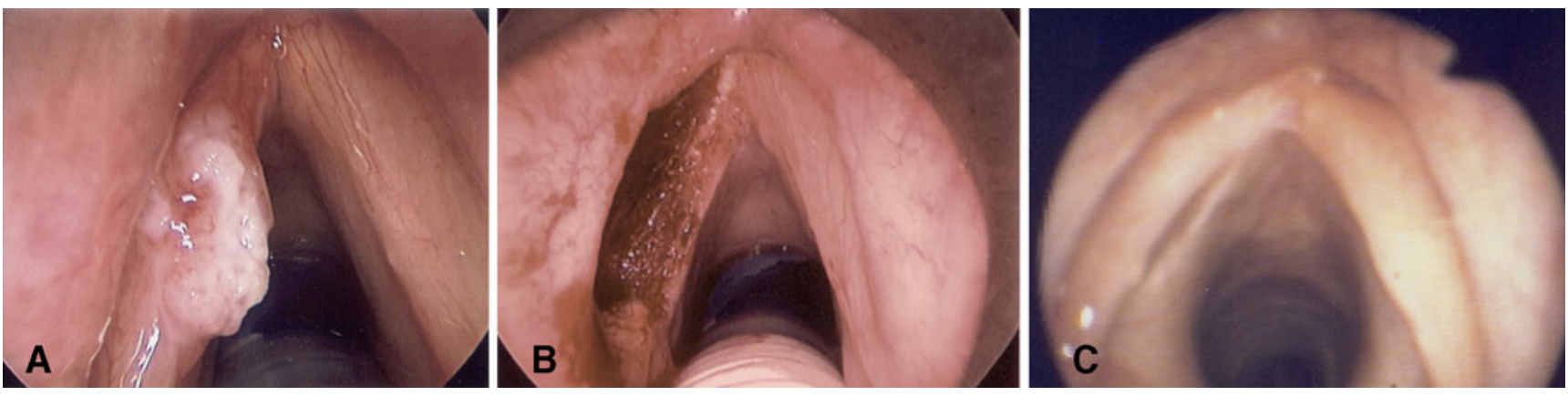

Fig. 10 a Image showing a patient with the diagnosis of glottic squamous cell carcinoma. b Immediate post-op, after removal of the tumor. c Results 6 months after the surgery was performed 
caused by extensive resection, preexisting laryngeal impairment, advanced age or poor health. Preoperative and postoperative assessment to determine the risk for aspiration is necessary to prevent development of aspiration pneumonia. Other complications encountered include: mucosal burns of the lips, oral cavity or oropharynx, dental injuries (loosened or chipped teeth), infection, dysphagia, and airway fires or burns [66-71].

\section{Summary}

TLM is an emerging technique for the treatment of laryngeal cancer and other head and neck cancers. Although several lasers may be used, most consider the $\mathrm{CO}_{2}$ laser the most versatile laser for the great majority of applications. Technological advances in microscope design, lasers, surgical instruments, energy beam profile, and delivery systems have made resection of tumors through the endoscope possible. Demonstration that tissues could be resected in a logical stepwise progression to systematically clear the field of tumor with oncologic margins eliminated the need to attempt "en bloc" removal. This expanded the extent of resections that can be safely performed. With new technology and new surgical techniques, incorporation of TLM into the surgical armamentarium requires commitment to learn the technically challenging procedures, and institutional commitment of resources to purchase necessary equipment to perform these procedures. Careful study of outcomes by Steiner and others [24, 38-41, 57] have demonstrated improved functional outcome with at least equal oncologic outcome. This has resulted in gradual but progressive expansion of the techniques globally.

Open Access This article is distributed under the terms of the Creative Commons Attribution Noncommercial License which permits any noncommercial use, distribution, and reproduction in any medium, provided the original author(s) and source are credited.

\section{References}

1. Jemal A, Siegel R, Ward E, Hao Y, Xu J, Murray T, Thun MJ (2008) Cancer statistics, 2008. CA Cancer J Clin 58(2):71-96

2. Barnes L, Tse LLY, Hunt JL, Brandwein-Gensler M, Urken M, Slootweg P, Gale N, Cardesa A, Zidar N, Boffetta P (2005) Tumours of the hypopharynx, larynx and trachea: Introduction. In: Barnes L, Eveson JW, Reichart P, Sidransky D (eds) World Health Organization Classification of Tumours Pathology and Genetics of Head and Neck Tumours. IARC Press, Lyon, pp 111-117

3. Hoffman HT, Porter K, Karnell LH, Cooper JS, Weber RS, Langer CJ, Ang KK, Gay G, Stewart A, Robinson RA (2006) Laryngeal cancer in the United States: changes in demographics, patterns of care, and survival. Laryngoscope 116(9 Pt 2 Suppl 111):1-13

4. Altieri A, Garavello W, Bosetti C, Gallus S, La Vecchia C (2005) Alcohol consumption and risk of laryngeal cancer. Oral Oncol 41 (10):956-965

5. La Vecchia C, Zhang ZF, Altieri A (2008) Alcohol and laryngeal cancer: an update. Eur J Cancer Prev 17(2):116-124

6. Menvielle G, Luce D, Goldberg P, Bugel I, Leclerc A (2004) Smoking, alcohol drinking and cancer risk for various sites of the larynx and hypopharynx. A case-control study in France. Eur J Cancer Prev 13(3):165-172

7. Menvielle G, Luce D, Goldberg P, Leclerc A (2004) Smoking, alcohol drinking, occupational exposures and social inequalities in hypopharyngeal and laryngeal cancer. Int J Epidemiol 33(4):799-806

8. Pelucchi C, Gallus S, Garavello W, Bosetti C, La Vecchia C (2008) Alcohol and tobacco use, and cancer risk for upper aerodigestive tract and liver. Eur J Cancer Prev 17(4):340-344

9. Qadeer MA, Colabianchi N, Vaezi MF (2005) Is GERD a risk factor for laryngeal cancer? Laryngoscope 115(3):486-491

10. Vaezi MF, Qadeer MA, Lopez R, Colabianchi N (2006) Laryngeal cancer and gastroesophageal reflux disease: a case-control study. Am J Med 119(9):768-776

11. Shangina O, Brennan P, Szeszenia-Dabrowska N, Mates D, Fabianova E, Fletcher T, t'Mannetje A, Boffetta P, Zaridze D (2006) Occupational exposure and laryngeal and hypopharyngeal cancer risk in Central and Eastern Europe. Am J Epidemiol 164 (4):367-375

12. Berrino F, Richiardi L, Boffetta P, Esteve J, Belletti I, Raymond L, Troschel L, Pisani P, Zubiri L, Ascunce N, Guberan E, Tuyns A, Terracini B, Merletti F (2003) Occupation and larynx and hypopharynx cancer: a job-exposure matrix approach in an international casecontrol study in France, Italy, Spain and Switzerland. Cancer Causes Control 14(3):213-223

13. Fakhry C, Gillison ML (2006) Clinical implications of human papillomavirus in head and neck cancers. J Clin Oncol 24 (17):2606-2611

14. Ragin CC, Modugno F, Gollin SM (2007) The epidemiology and risk factors of head and neck cancer: a focus on human papillomavirus. J Dent Res 86(2):104-114

15. Schlecht NF, Burk RD, Adrien L, Dunne A, Kawachi N, Sarta C, Chen Q, Brandwein-Gensler M, Prystowsky MB, Childs G, Smith RV, Belbin TJ (2007) Gene expression profiles in HPV-infected head and neck cancer. J Pathol 213(3):283-293

16. Copper MP, Jovanovic A, Nauta JJ, Braakhuis BJ, de Vries N, van der Waal I, Snow GB (1995) Role of genetic factors in the etiology of squamous cell carcinoma of the head and neck. Arch Otolaryngol Head Neck Surg 121(2):157-160

17. Armstrong WB, Netterville JL (1995) Anatomy of the larynx, trachea, and bronchi. Otolaryngol Clin North Am 28(4):685-699

18. Merati AL, Rieder AA (2003) Normal endoscopic anatomy of the pharynx and larynx. Am J Med 115(Suppl 3A):10S-14S

19. Noordzij JP, Ossoff RH (2006) Anatomy and physiology of the larynx. Otolaryngol Clin North Am 39(1):1-10

20. AJCC cancer staging manual (2002) Greene FL (ed) Springer, Berlin Heidelberg New York, 435 pp

21. Ogura JH, Thawley SE (1978) Glottic competence following removal of arytenoid in partial laryngopharyngectomy and subtotal supraglottic laryngectomy. Laryngoscope 88(3):528-529

22. Ogura JH (1979) "How I do it"-head and neck. A targeted problem and its solution. Hyoid muscle flap reconstruction in subtotal supraglottic laryngectomy: a more rapid rehabilitation of deglutition. Laryngoscope 89(9 Pt 1):1522-1524

23. Tufano RP, Stafford EM (2008) Organ preservation surgery for laryngeal cancer. Otolaryngol Clin North Am 41(4):741-755, vi

24. Ambrosch P (2007) The role of laser microsurgery in the treatment of laryngeal cancer. Curr Opin Otolaryngol Head Neck Surg 15(2):82-88 
25. Cortesina G, De Stefani A, Cavalot A, Albera R, Rosso P, Bussi M (2000) Current role of radiotherapy in the treatment of locally advanced laryngeal carcinomas. J Surg Oncol 74(1):79-82

26. Wolf GT (2001) Options for preserving the larynx in patients with advanced laryngeal and hypopharyngeal cancer. Ear Nose Throat J 80(12):897-901

27. de Bree R, Leemans CR (2010) Recent advances in surgery for head and neck cancer. Curr Opin Oncol 22(3):186-193

28. Sadri M, McMahon J, Parker A (2006) Management of laryngeal dysplasia: a review. Eur Arch Otorhinolaryngol 263(9):843-852

29. The Department of Veterans Affairs Laryngeal Cancer Study Group (1991) Induction chemotherapy plus radiation compared with surgery plus radiation in patients with advanced laryngeal cancer. N Engl J Med 324(24):1685-1690

30. Forastiere AA, Goepfert H, Maor M, Pajak TF, Weber R, Morrison W, Glisson B, Trotti A, Ridge JA, Chao C, Peters G, Lee DJ, Leaf A, Ensley J, Cooper J (2003) Concurrent chemotherapy and radiotherapy for organ preservation in advanced laryngeal cancer. N Engl J Med 349(22):2091-2098

31. Machtay M, Rosenthal DI, Hershock D, Jones H, Williamson S, Greenberg MJ, Weinstein GS, Aviles VM, Chalian AA, Weber RS (2002) Organ preservation therapy using induction plus concurrent chemoradiation for advanced resectable oropharyngeal carcinoma: a University of Pennsylvania Phase II Trial. J Clin Oncol 20(19):3964-3971

32. Agrawal N, Goldenberg D (2008) Primary and salvage total laryngectomy. Otolaryngol Clin North Am 41(4):771-780, vii

33. Jackson C (1915) Malignant disease of the epiglottis. In: Jackson C, Killian G, Hageman JA (eds) Peroral endoscopy and laryngeal surgery. Saint Louis, MO, Laryngoscope Co. pp 438-439

34. Jackson C (1939) Endoscopic removal of cancer of the epiglottis. In: Jackson C, Jackson CL (eds) Cancer of the larynx. W.B. Saunders Company, Philadelphia, p 52

35. Strong MS, Jako GJ (1972) Laser surgery in the larynx. Early clinical experience with continuous $\mathrm{CO}_{2}$ laser. Ann Otol Rhinol Laryngol 81(6):791-798

36. Strong MS (1975) Laser excision of carcinoma of the larynx. Laryngoscope 85(8):1286-1289

37. Vaughan CW, Strong MS, Jako GJ (1978) Laryngeal carcinoma: transoral treatment utilizing the $\mathrm{CO}_{2}$ laser. Am J Surg 136(4):490-493

38. Steiner W (1988) Experience in endoscopic laser surgery of malignant tumours of the upper aero-digestive tract. Adv Otorhinolaryngol 39:135-144

39. Steiner W (1993) Results of curative laser microsurgery of laryngeal carcinomas. Am J Otolaryngol 14(2):116-121

40. Steiner W, Ambrosch P, Hess CF, Kron M (2001) Organ preservation by transoral laser microsurgery in piriform sinus carcinoma. Otolaryngol Head Neck Surg 124(1):58-67

41. Steiner W, Fierek O, Ambrosch P, Hommerich CP, Kron M (2003) Transoral laser microsurgery for squamous cell carcinoma of the base of the tongue. Arch Otolaryngol Head Neck Surg 129(1):36-43

42. Grant DG, Salassa JR, Hinni ML, Pearson BW, Hayden RE, Perry WC (2008) Transoral laser microsurgery for recurrent laryngeal and pharyngeal cancer. Otolaryngol Head Neck Surg 138(5):606-613

43. Hinni ML, Salassa JR, Grant DG, Pearson BW, Hayden RE, Martin A, Christiansen H, Haughey BH, Nussenbaum B, Steiner W (2007) Transoral laser microsurgery for advanced laryngeal cancer. Arch Otolaryngol Head Neck Surg 133(12):1198-1204

44. Grant DG, Salassa JR, Hinni ML, Pearson BW, Hayden RE, Perry WC (2007) Transoral laser microsurgery for untreated glottic carcinoma. Otolaryngol Head Neck Surg 137(3):482-486

45. Grant DG, Salassa JR, Hinni ML, Pearson BW, Hayden RE, Perry WC (2007) Transoral laser microsurgery for carcinoma of the supraglottic larynx. Otolaryngol Head Neck Surg 136(6):900-906

46. Cabanillas R, Rodrigo JP, Llorente JL, Suarez V, Ortega P, Suarez C (2004) Functional outcomes of transoral laser surgery of supraglottic carcinoma compared with a transcervical approach. Head Neck 26 (8):653-659

47. Zeitels SM, Burns JA (2006) Laser applications in laryngology: past, present, and future. Otolaryngol Clin North Am 39(1):159-172

48. Zeitels SM, Burns JA, Lopez-Guerra G, Anderson RR, Hillman RE (2008) Photoangiolytic laser treatment of early glottic cancer: a new management strategy. Ann Otol Rhinol Laryngol Suppl 199:3-24

49. Cabanillas R, Ortega C, Rodrigo JP, Llorente JL, Ortega P, Suarez C (2005) Functional outcomes of transoral laser surgery of supraglottic carcinoma. Acta Otorrinolaringol Esp 56(4):156-160

50. Devaiah AK, Shapshay SM, Desai U, Shapira G, Weisberg O, Torres DS, Wang Z (2005) Surgical utility of a new carbon dioxide laser fiber: functional and histological study. Laryngoscope 115(8):1463-1468

51. Jacobson AS, Woo P, Shapshay SM (2006) Emerging technology: flexible $\mathrm{CO}_{2}$ laser WaveGuide. Otolaryngol Head Neck Surg 135 (3):469-470

52. Zeitels SM, Akst LM, Burns JA, Hillman RE, Broadhurst MS, Anderson RR (2006) Office-based 532-nm pulsed KTP laser treatment of glottal papillomatosis and dysplasia. Ann Otol Rhinol Laryngol 115(9):679-685

53. Ossoff RH, Garrett CG, Reinisch L (2005) Laser surgery: basic principles and safety considerations. In: Cummings CW (ed) Cummings otolaryngology: head and neck surgery, 4th edn. Elsevier Mosby, Philadelphia, pp 214-230

54. Philipp CM, Berlien HP (2005) Basic principles of medical laser technology. In: Huettenbrink KB (ed) Lasers in otorhinolaryngology. Thieme, New York

55. Koufman JA, Rees CJ, Frazier WD, Kilpatrick LA, Wright SC, Halum SL, Postma GN (2007) Office-based laryngeal laser surgery: a review of 443 cases using three wavelengths. Otolaryngol Head Neck Surg 137(1):146-151

56. Ossoff RH (1989) Laser safety in otolaryngology—-head and neck surgery: anesthetic and educational considerations for laryngeal surgery. Laryngoscope 99(8 Pt 2 Suppl 48):1-26

57. Steiner W, Ambrosch P (2000) Endoscopic laser surgery of the upper aerodigestive tract. Thieme, New York

58. Eckel HE (1997) Endoscopic laser resection of supraglottic carcinoma. Otolaryngol Head Neck Surg 117(6):681-687

59. Rudert HH, Werner JA, Hoft S (1999) Transoral carbon dioxide laser resection of supraglottic carcinoma. Ann Otol Rhinol Laryngol 108 (9):819-827

60. Karatzanis AD, Psychogios G, Zenk J, Waldfahrer F, Hornung J, Velegrakis GA, Iro H (2009) Comparison among different available surgical approaches in T1 glottic cancer. Laryngoscope 119(9):1704-1708

61. Fisher JC (1996) Basic biophysical principles of resurfacing of human skin by means of the carbon dioxide laser. J Clin Laser Med Surg 14(4):193-210

62. Remacle M, Lawson G, Nollevaux MC, Delos M (2008) Current state of scanning micromanipulator applications with the carbon dioxide laser. Ann Otol Rhinol Laryngol 117(4):239-244

63. Steiner W, Ambrosch P, Rodel RM, Kron M (2004) Impact of anterior commissure involvement on local control of early glottic carcinoma treated by laser microresection. Laryngoscope 114 (8):1485-1491

64. Manola M, Moscillo L, Costa G, Barillari U, Lo Sito S, Mastella A, Ionna $\mathrm{F}$ (2008) Conservative laser microsurgery for T1 glottic carcinoma. Auris Nasus Larynx 35(1):141-147

65. Jackel MC, Martin A, Steiner W (2007) Twenty-five years experience with laser surgery for head and neck tumors: report of an international symposium, Göttingen, Germany, 2005. Eur Arch Otorhinolaryngol 264(6):577-585

66. Corvo MA, Inacio A, Mello MB, Eckley CA, Duprat Ade C (2007) Extra-laryngeal complications of suspension laryngoscopy. Braz J Otorhinolaryngol 73(6):727-732 
67. Klussmann JP, Knoedgen R, Wittekindt C, Damm M, Eckel HE (2002) Complications of suspension laryngoscopy. Ann Otol Rhinol Laryngol 111(11):972-976

68. Preuss SF, Cramer K, Klussmann JP, Eckel HE, Guntinas-Lichius O (2009) Transoral laser surgery for laryngeal cancer: outcome, complications and prognostic factors in 275 patients. Eur J Surg Oncol 35(3):235-240

69. Rosen CA, Andrade Filho PA, Scheffel L, Buckmire R (2005) Oropharyngeal complications of suspension laryngoscopy: a prospective study. Laryngoscope 115(9):1681-1684
70. Vilaseca-Gonzalez I, Bernal-Sprekelsen M, Blanch-Alejandro JL, Moragas-Lluis $\mathrm{M}$ (2003) Complications in transoral $\mathrm{CO}_{2}$ laser surgery for carcinoma of the larynx and hypopharynx. Head Neck 25(5):382-388

71. Pearson BW, Salassa JR, Hinni ML (2005) Transoral laser micro resection of advanced laryngeal tumors. In: Cummings CW, Flint PW, Haughey BH, Robbins KT, Thomas JR, Harker LA, Richardson MA, Schuller DE (eds) Cummings otolaryngology: head and neck surgery, 4th edn. Elsevier Mosby, Philadelphia 